\title{
TEMPESTITOS COM INFLUÊNCIA GLACIAL DA FORMAÇÃO PLAYA HERMOSA (NEOPROTEROZÓICO), PIRIÁPOLIS, URUGUAI
}

\author{
GELSON LUÍS FAMBRINI ${ }^{1}$, RENATO PAES-DE-ALMEIDA ${ }^{2,3}$, CLAUDIO RICCOMINI $^{2,4}$ \\ \& ANTONIO ROMALINO S. FRAGOSO-CESAR ${ }^{2}$
}

\begin{abstract}
STORM-WAVE INFLUENCED GLACIMARINE DEPOSITS OF THE PLAYA HERMOSA FORMATION (NEOPROTEROZOIC), PIRIÁPOLIS, URUGUAY Storm-wave influenced glacimarine deposits of the Playa Hermosa Formation (Neoproterozoic) crop out along the beaches of Playa Grande and Playa Hermosa (town of Piriápolis, southern Uruguay). These deposits are characterized by fining-upward cycles composed, from the base to the top of successions of: (i) conglomerates and sandy-rhythmites in decimetric layers showing similar processes of rain-out, which pass to, (ii) finely laminated and rippled centimetric sandstones with deformed beds and outsized clast up to $71 \mathrm{~cm}$ of size, with associated bending and rucking structures, (iii) well-sorted fine centimetric sandstones with swaley and hummocky cross-stratification and wave ripples interpreted as sandy tempestites which are recovered by (iv) finely laminated rhythmtes affected by intrusions of trachytes, syenites and rhyolites of the Sierra de Animas Suite (570-550 Ma). The main evidences for a glaciomarine origin includes: (i) the confirmed presence of a dropstone in fine-grained sediments indicating a hydrodynamic paradox, (ii) the presence of massive conglomeratic sandstone facies formed by rain-out processes and (iii) according to specialized literature the paleomagnetic data indicative of a low to intermediate position for the Rio de La Plata Craton in the Neoproterozoic. The loneclast was interpreted as a dropstone due to the anomalous size, the hydrodynamic paradox and the composition, farther that other forms of transport are rejected here (e.g. organic transport).
\end{abstract}

Keywords: glaciation, tempestites, turbidites, facies analysis, Playa Hermosa formation, Neoproterozoic, Uruguay

\begin{abstract}
Resumo Depósitos glaciogênicos afetados por ondas de tempestade (tempestitos) de idade provável neoproterozóica ocorrem na região de Piriápolis, no extremo sul do Uruguai. Estes depósitos fazem parte da Formação Playa Hermosa que aflora ao longo da orla das praias Grande e Hermosa na referida cidade. As rochas desta unidade incluem ciclos granodecrescentes formados, da base para o topo, por: (i) sucessões decimétricas de conglomerados com grânulos e seixos, esporadicamente até calhaus, e arenitos conglomeráticos com evidências de processos de chuva de detritos a partir de blocos flutuantes de gelo (rain-out) que passam para (ii) sucessões centimétricas de arenitos finos a muito finos laminados e com marcas onduladas, bem selecionados, com níveis deformados, portando clasto isolado de tamanho anômalo (outsized-clast), de $71 \mathrm{~cm}$ de eixo maior, que deforma as camadas subjacentes, e ritmitos heterolíticos que culminam com (iii) sucessões centimétricas de arenitos finos, bem selecionados, com estratificações cruzadas tipo swaley e hummocky interpretados como depósitos de tempestitos que são, por sua vez, recobertos na porção superior da exposição por (iv) ritmitos laminados afetados por intrusões (traquitos, sienitos e riolitos) pertencentes à Suíte Sierra de Animas (570-550 Ma). As principais evidências que permitiram inferir ambiente glaciogênico para esses depósitos são: (i) a presença de clasto isolado em meio a sedimentos finos constituindo um clasto caído (dropstone) indicando paradoxo hidrodinâmico, (ii) evidências de aporte de material areno-rudáceo por chuva de detritos a partir de blocos de gelo flutuantes e (iii) dados paleomagnéticos (de acordo com a bibliografia especializada) que indicam uma posição paleogeográfica para o Cráton Rio de La Plata e regiões vizinhas em latitudes baixas e intermediárias e, por consequiência, próximo ao pólo terrestre no Neoproterozóico. O clasto isolado foi interpretado como clasto caído devido às suas características intrínsecas (e.g. tamanho anômalo, paradoxo hidrodinâmico) e também pelo fato de que outras formas de transporte da clastos são aqui descartadas (e.g. transporte orgânico).
\end{abstract}

Palavras-chave: glaciação, tempestitos, turbiditos, análise de fácies, Formação Playa Hermosa, Neoproterozóico, Uruguai

INTRODUÇÃO Descrições de depósitos glaciomarinhos são abundantes na literatura geológica, incluindo exemplos précambrianos (Miall 1983, Karfunkel \& Hoppe 1988, Eyles 1988, Eyles \& Eyles 1989, Eyles 1990, Alvarenga \& Trompette 1992), paleozóicos (Eyles et al. 1985, Caputo \& Crowell 1985, Visser \& Loock 1987, O’Brien 1989, Eyles et al. 1993, Rocha-Campos et al. 2000, Gesicki et al. 2002) e cenozóicos (Eyles \& Eyles 1984, Eyles et al. 1985, McCabe 1986, Eyles \& McCabe 1989). Entretanto, o registro de depósitos glaciogênicos influenciados por ondas de tempestades é pouco freqüente (e.g. Soares 1998 e Eyles et al.
1998). A Formação Playa Hermosa representa depósitos turbidíticos sob influência glacial com ação de ondas de tempestades (tempestitos) na porção superior.

Neste trabalho são descritas e interpretadas as exposições naturais da seção-tipo da Formação Playa Hermosa situadas na faixa litorânea da Cidade de Piriápolis, ao longo das praias Grande e Hermosa, sul do Uruguai. Esta unidade foi definida por Masquelin \& Sánchez-Bettucci (1993) compreendendo uma sucessão inicial de arenitos, siltitos, ritmitos e conglomerados subordinados, e uma sucessão superior com ignimbritos, traquitos, conglomera-

Instituto de Geociências, Universidade de São Paulo, Rua do Lago, 562, CEP: 05508-900, São Paulo, SP. Fone: (011) 3091-3914 / 3994, Fax: 55 (11) 3091-4129 (g_fambrini@yahoo.com).

1 - Programa de Pós-Graduação em Geoquímica e Geotectônica, Bolsista da FAPESP (98/03682-3).

2 - Departamento de Geologia Sedimentar e Ambiental (GSA) - E-mail: riccomin@usp.br

3 - Programa de Pós-Graduação em Geologia Sedimentar - E-mail: rpalmeida@ rocketmail.com

4 - Bolsista de produtividade em pesquisa do Conselho Nacional de Desenvolvimento Científico e Tecnológico (CNPq) 
dos e arenitos com estratificação cruzada, expostos nas praias Grande, Hermosa e Verde. Os autores correlacionaram-na com depósitos supostamente similares do Brasil (e.g. Grupo Camaquã), interpretando-a como gerada por correntes de turbidez.

Sánchez-Bettucci \& Pazos (1996) analisaram os ambientes deposicionais da porção siliciclástica da Formação Playa Hermosa. A porção inferior desta unidade foi estudada por Pazos et al. $(1998,2003)$, que reconheceram pioneiramente a origem glacial dos sedimentos da Formação Playa Hermosa com base na presença de diamictitos e ritmitos, estes contendo clasto de tamanho anômalo com estrias longitudinais e irregulares, interpretado como clasto caído (dropstone) a partir de blocos de gelo flutuantes (ice-rafting).

Trabalhos de campo recentes resultaram na presente proposta de redefinição da Formação Playa Hermosa envolvendo apenas a sucessão siliciclástica, excluindo-se os conglomerados com derivação vulcânica e as intrusões de traquitos e sienitos e diques de riolitos, já pertencentes à Suíte Intrusiva Sierra de Animas. Na área estudada, a unidade tem direção geral NE, inclinação das camadas em torno de 50-60 para NW e fraturas de direção N20-30E e N60E.

As exposições da Formação Playa Hermosa foram estudadas através de levantamento de seções colunares e análise de fácies para a interpretação de sistemas deposicionais. Estes estudos permitiram o reconhecimento de um sistema deposicional com influência glacial em águas relativamente rasas, com ação de ondas de tempestade na porção de topo da seção estudada. O registro de depósitos glaciais na Formação Playa Hermosa, conforme já apontado por Pazos et al. (1998, 2003), abre a possibilidade de correlação com importantes eventos glaciais neoproterozóicos (Hambrey \& Harland 1985, Eyles 1993, Eyles \& Young 1993, Hoffman et al. 1998, Hyde et al. 2000, Hoffman \& Schrag 2000).

CONTEXTO GEOLÓGICO REGIONAL A FormaçãoPlaya Hermosa situa-se na extremidade meridional do Escudo Gaúcho. Este escudo reúne os complexos metamórficos e plutônicos précambrianos aflorantes no Rio Grande do Sul (RS) e Uruguai, reunidos no Cráton Rio de La Plata, no Cinturão Dom Feliciano e no Terreno Rio Vacacaí (Fragoso-Cesar 1980, 1991) (Fig. 1). Sobre este escudo, sobretudo na porção centro-sul do RS e no sul do Uruguai, ocorrem testemunhos de coberturas não-metamórficas com deformação variada e idades situadas no Neoproterozóico III Tardio e no Paleozóico Inferior. Estas coberturas compreendem o Grupo Camaquã no RS (Fragoso-Cesar et al. 2000) e diversas ocorrências no Uruguai (e.g. formações Sierra de Animas, Las Ventanas, Barriga Negra e San Carlos) (Fragoso-Cesar et al. 1987, Masquelin \& Sánchez-Bettucci 1993, Sánchez-Bettucci \& Pazos 1996).

No Uruguai, além destes testemunhos, afloram outros com características tectônicas e metamórficas análogas, porém de situação estratigráfica ambígua, podendo representar fácies não metamorfizadas ou anquimetamorfizadas de unidades supracrustais metamórficas do embasamento. Dentre estes, destacam-se a Formação Piedras de Afilar, os Calcários de Polanco e a Formação Playa Hermosa, todas ocorrendo ao longo do limite do Cinturão Dom Feliciano com o Cráton Rio de La Plata. Embora estas unidades uruguaias tenham sido correlacionadas às coberturas nãometamórficas por diversos autores (e.g. Bossi et al. 1975, Preciozzi et al. 1985), outros, no entanto, têm apontado correlações entre a Formação Piedras de Afilar e os Calcáreos de Polanco com as coberturas siliciclástico-carbonáticas metamórficas (Grupo Lavalleja) do Cinturão Dom Feliciano no Uruguai (e.g. Caorsi \& Goñi 1958, Fragoso-Cesar et al. 1987).

A Formação Playa Hermosa, que constitui o objeto do presente estudo, foi correlacionada por Masquelin \& Sánchez-Bettucci (1993) e Sánchez-Bettucci \& Pazos (1996) às coberturas nãometamórficas, tanto do Uruguai quanto do RS (Grupo Camaquã).

MÉTODOS UTILIZADOS Os métodos empregados neste trabalho compreenderam a descrição e medição de exposições da Formação Playa Hermosa em afloramentos às margens do Rio de La Plata na Cidade de Piriápolis. A descrição da unidade e a interpretação dos processos sedimentares foram realizadas pela análise de fácies e de sistemas deposicionais de acordo com Walker \& James (1992) e Miall (2000), em especial a relativa aos ambientes dominados por ondas de tempestade com base em Harms et al. (1975), De Raaf et al. (1977), Duke (1990), Southard et al. (1990), Cheel \& Leckie (1992), incluindo as seguintes etapas: (i) reconhecimento e descrição pormenorizada das camadas aflorantes, (ii) elaboração de esquema de litofácies com base em Eyles et al. (1983), Visser \& Loock (1987) e Eyles et al. (1993), inspiradas em Miall (1978), (iii) interpretação dos processos de transporte e deposição responsáveis pela formação de cada fácies, (iv) levantamento de seções colunares com medida da espessura das camadas e posterior descrição detalhada, (v) interpretação do paleoambiente deposicional com base na associação das fácies, relação entre os processos e comparação com depósitos similares descritos na literatura. Na codificação das litofácies aadotou-se siglas com duas letras, a primeira, maiúscula, referente à litologia ou granulometria predominante e a última, minúscula, referente à principal estrutura sedimentar ou feição característica da fácies. Se necessário, uma terceira letra foi adicionada, entre as duas anteriores, objetivando complementar a caracterização granulométrica. A codificação seguiu, sempre que possível, a adoção de siglas utilizadas em trabalhos semelhantes, segundo a nomenclatura de língua inglesa já relativamente padronizada.

FORMAÇÃO PLAYA HERMOSA Definida por Masquelin \& Sánchez-Bettucci (1993), a Formação Playa Hermosa possui restritas ocorrências próximas à Cidade de Piriápolis, constituindo um pequeno $(<10 \mathrm{~km})$ e estreito (apenas localmente ultrapassando $100 \mathrm{~m}$ ) cordão de afloramentos transversal ao empilhamento estratigráfico, exposto ao longo dos balneários de Playa Grande, Playa Hermosa e Playa Verde (Fig. 2). A unidade também ocorre fora da orla, mas com área ainda mais restrita (e.g. Parque de Las Cascadas). Nas porções basal e intermediária a unidade consiste de ciclos granodecrescentes de sucessões decimétricas de conglomerados de grânulos e seixos, esporadicamente até calhaus, e arenitos conglomeráticos que passam a arenitos finos decimétricos a centimétricos laminados com marcas onduladas, ambos de cor parda, que apresentam níveis deformados onde no topo ocorrem estratificações cruzadas hummocky e swaley. Para o topo da unidade, a associação está cortada por diques, veios e apófises de rochas da Suíte Sierra de Animas. Esta unidade está sendo aqui reformulada pela exclusão dos depósitos vulcânicos, limitados à Suíte Sierra de Animas. A designação Formação Playa Hermosa, restrita ao pacote sedimentar, é anterior ao magmatismo da Suíte Sierra de Animas (Fig. 3), na qual foram obtidas idades radiométricas entre 570 e 525 Ma (Bossi et al. 1993, Cingolani et al. 1993, Sánchez-Bettucci \& Linares 1996).

ANÁLISE DE FÁCIES DA FORMAÇÃO PLAYA HERMOSA Foram reconhecidas as seguintes fácies sedimentares, exemplificadas nas seções colunares levantadas para este trabalho (Fig. 4): (i) conglomerados maciços com abundantes clastos 


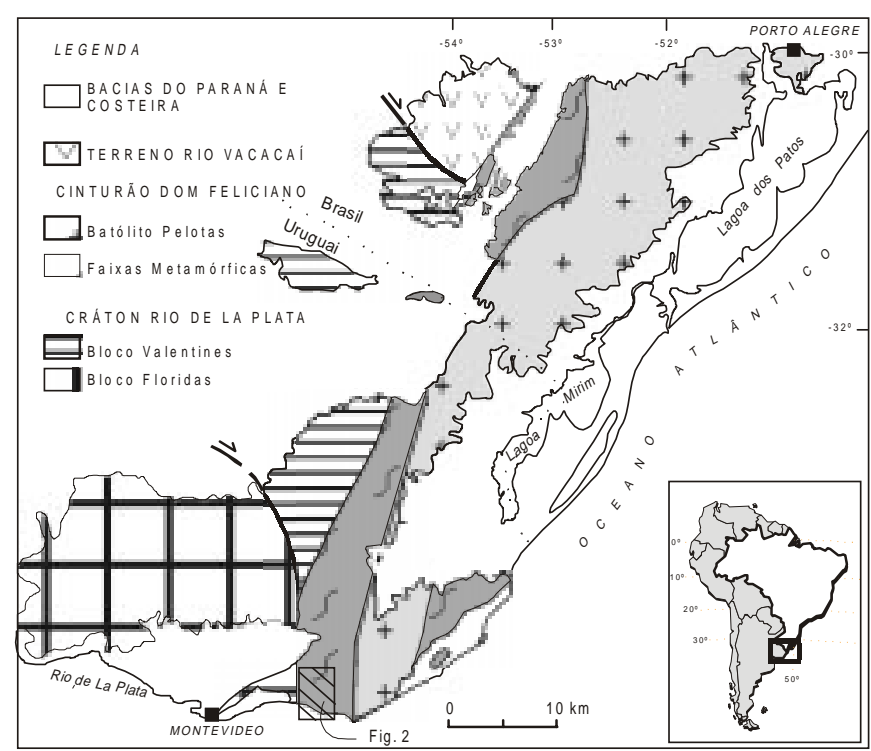

Figura 1- Esquema do Escudo Gaúcho no Rio Grande do Sul e Uruguai com destaque para o Cráton Rio de La Plata, Cinturão Dom Feliciano e Terreno Rio Vacacai. Simplificado de FragosoCesar (1990, 1991). Vide localização da Fig. 2.

intraformacionais (Gm - massive conglomerates), (ii) arenitos conglomeráticos maciços a gradados (Spm - massive pebbly sandstones), (iii) arenitos maciços (Sm - massive sandstones), (iv) arenitos com laminação ondulada ( $\mathrm{Sr}$ - rippled laminated sandstones), (v) arenitos com laminação plano-paralela (Sh horizontally laminated sandstones), (vi) arenitos com laminação convoluta (Sc - convolute laminated sandstones), (vii) arenitos laminados com clasto caído ( $S d$ - sandstones with dropstone), (viii) arenitos com estratificações cruzadas swaley e hummocky (SH - hummocky and swaley cross-stratified sandstones), (ix) ritmitos heterolíticos $(H w)$ e (x) ritmitos laminados $(R l$-laminated to rippled rhythmites). A Tabela 1 resume as fácies identificadas.

Fácies de Conglomerados Maciços (Gm) Esta fácies compõe-se de conglomerados maciços (espessura de 0,5 a 1,5 m) sustentados por arcabouço de grânulo a seixo pequeno $(0,4$ a 3,0 cm), com clastos angulosos a subarredondados de quartzo de veio e quartzito, sem matriz fina, com má seleção granulométrica e sem organização interna. As camadas comumente exibem base erosiva e geometria irregular. Ocorrem com freqüência clastos intraformacionais da granulação seixo e, mais raramente, calhau de até $20 \mathrm{~cm}$ de arenitos finos laminados, freqüentemente contorcidos, argilitos e siltitos (Fig. 5). Os clastos possuem limites e laminação interna deformados, mas em alguns casos mostram estruturas internas bem preservadas, em clastos tabulares paralelos às camadas.

A presença de intraclastos deformados é interpretada como resultado da erosão de camadas inferiores inconsolidadas porém coesas devido ao seu conteúdo argiloso, e denota a alta energia do processo de transporte. O caráter maciço e a falta de organização interna sugerem deposição direta de material em suspensão como resultado da rápida desestabilização de uma corrente turbulenta de alta densidade (Lowe 1982), o que, por outro lado, inviabilizam a hipótese de transporte por tração em corrente subaquática. A possibilidade de transporte por carpetes de tração, com ação de pressões dispersivas de colisão de partículas, é desfavorecida por

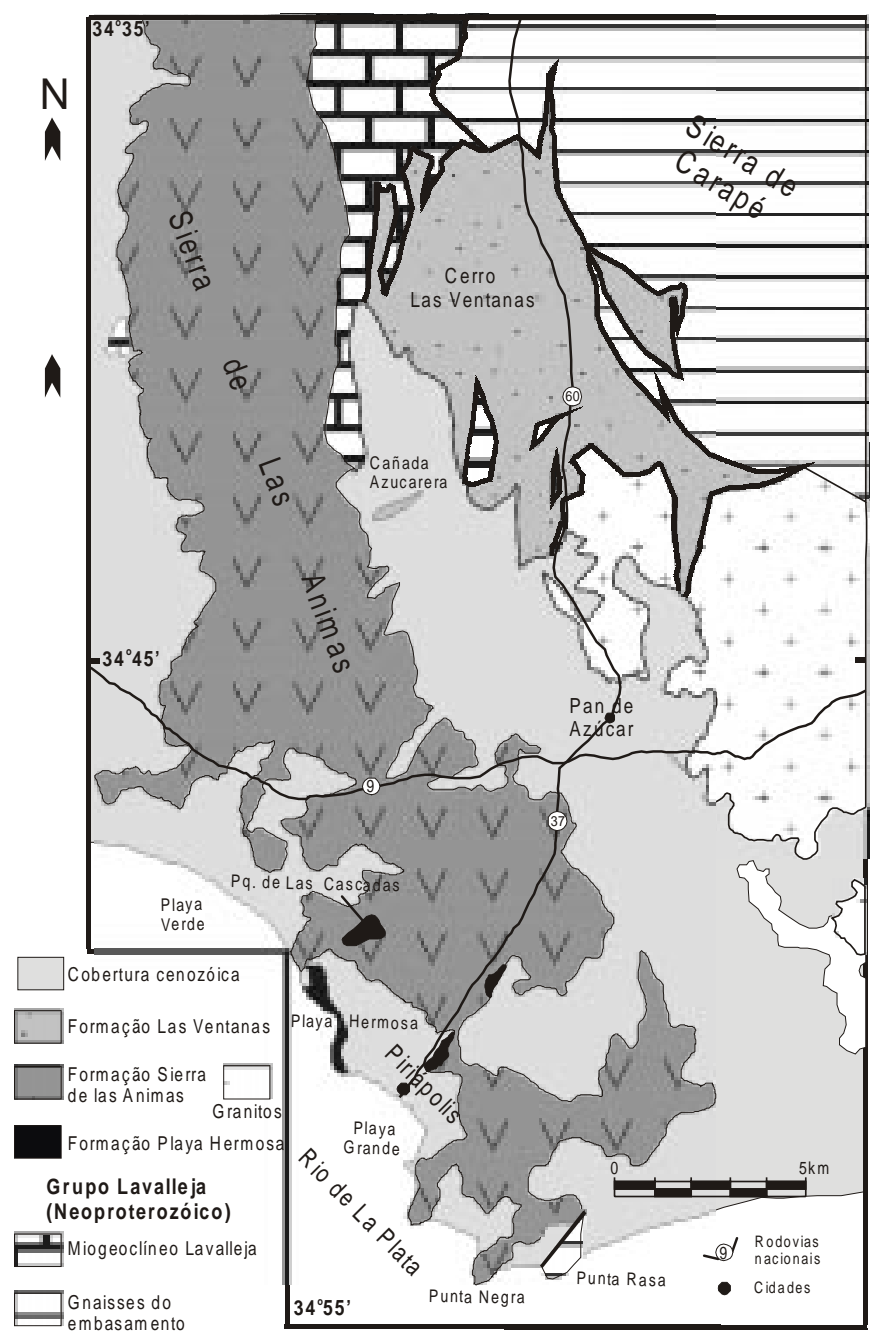

Figura 2- Esboço geológico do extremo sul do Uruguai na região de Piriápolis (simplificado de Sánchez-Bettucci 1998).

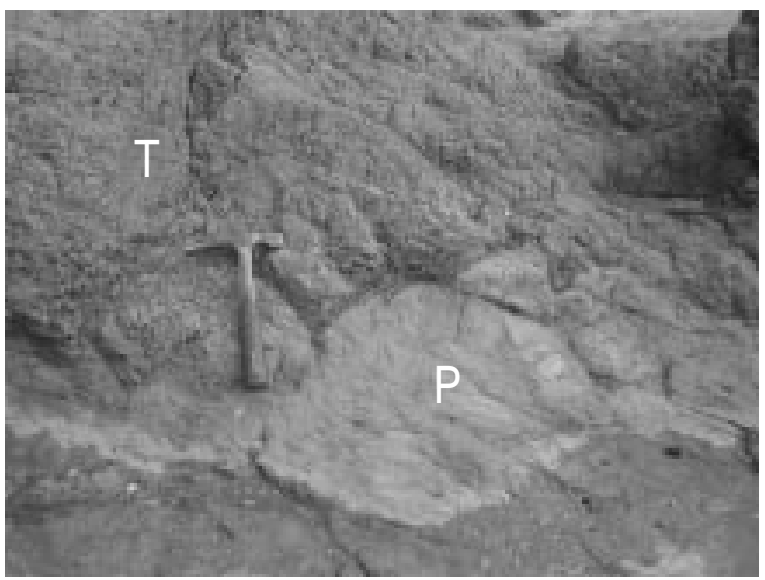

Figura 3- Intrusão de traquitos de granulação média $(T)$ da Suíte Sierra de Animas em pelitos laminados $(P)$ da Formação Playa Hermosa na localidade homônima. Martelo como escala mede $41 \mathrm{~cm}$. 


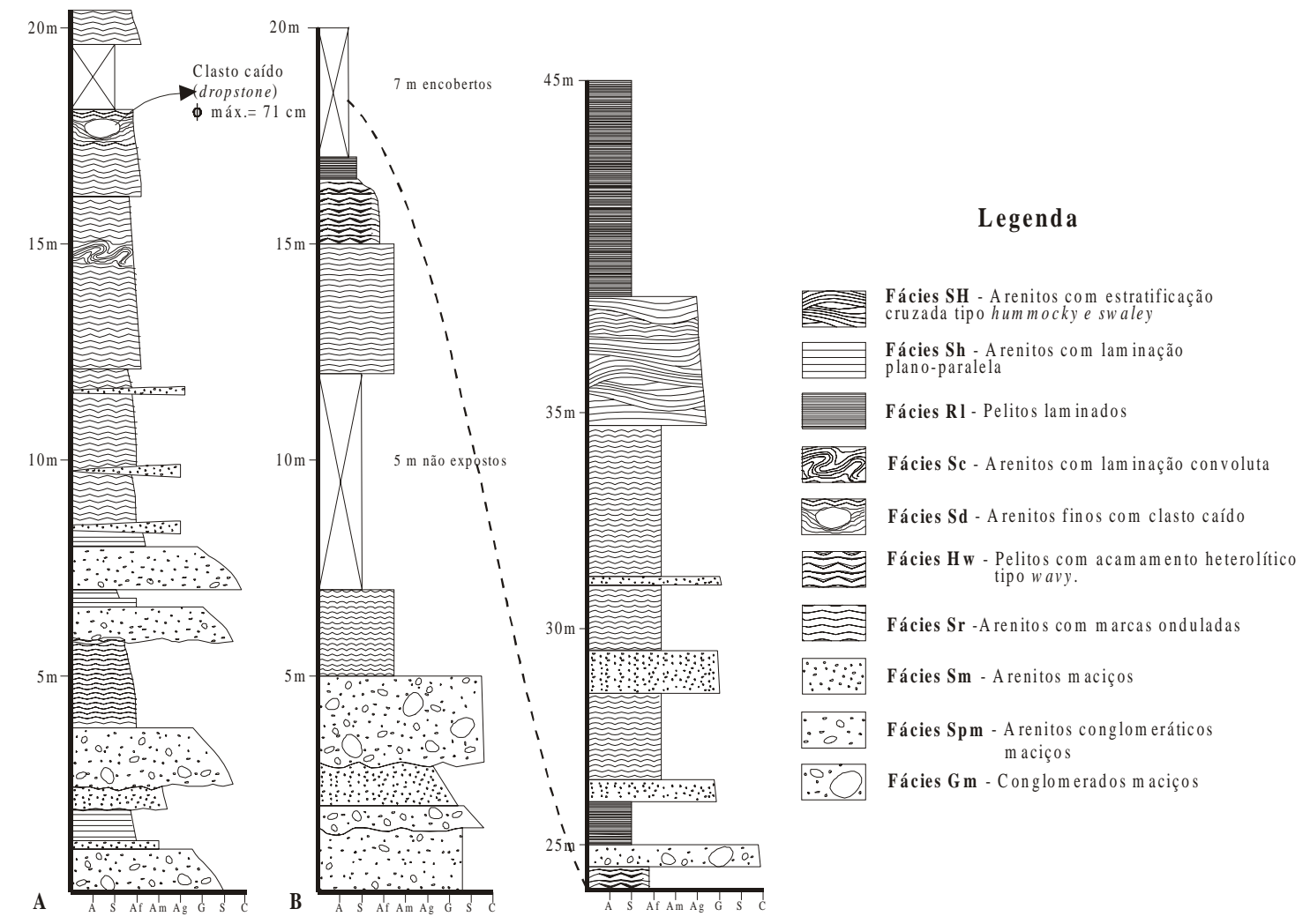

Figura 4 - Seções colunares de detalhe da Formação Playa Hermosa em sua localidade-tipo.

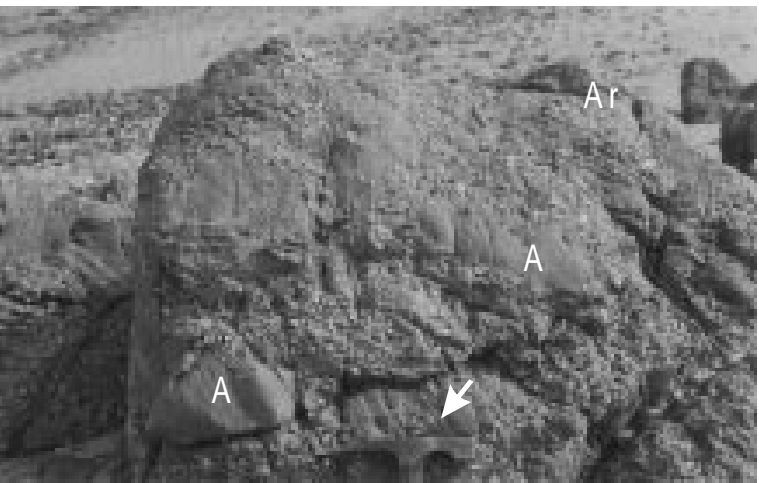

Figura 5 - Fácies Gm (conglomerados maciços) com clastos intraformacionais de arenitos finos (Ar), argilitos e siltitos, laminados, comumente contorcidos (A). Seta indica escala. Orla de Playa Grande.

não ocorrer gradação inversa e pela elevada espessura de algumas das camadas.

Fácies de Arenitos Conglomeráticos Maciços (Spm) Os arenitos conglomeráticos compõem-se de pacotes decimétricos de geometria tabular a lenticular, que lhes conferem espessura irregular (entre 30 e $60 \mathrm{~cm}$ ), de arenitos grossos a finos, maciços, com raros seixos esparsos e abundantes grânulos, concentrados em lentes e bolsões irregulares decimétricos, porém de contornos bem definidos, separados por porções de arenitos finos com melhor seleção (Fig.
6). Os grânulos e seixos são compostos por fragmentos de quartzo e quartzito, subangulosos a subarredondados. Ocorrem associados à Fácies de Arenitos com Marcas Onduladas ( $\mathrm{Sr}$ ), em contatos bruscos, e também à Fácies de Arenitos Maciços $(\mathrm{Sm})$, com limites entre camadas geralmente mal definidos e transicionais.

A presença de grânulos e seixos esparsos e, principalmente, sua concentração em lentes e bolsões irregulares, sugere rápida deposição a partir de suspensão, sem transporte paralelo à camada. Um processo capaz de explicar tal organização é o de chuva de detritos (rain-out no sentido de Eyles \& Eyles 1992), caracterizado pelo acréscimo vertical de depósitos mal selecionados desprendidos, a altas taxas, da base de blocos flutuantes de gelo. A possibilidade de uma origem relacionada a fluxos gravitacionais de alta densidade é desfavorecida pela clara distinção entre os corpos irregulares com concentração de grânulos e as porções de arenitos melhor selecionados que os envolvem, feição esta que não seria preservada no caso de transporte por fluxo granular (sensu Lowe 1982), que dá origem a camadas homogeneamente maciças ou com gradação inversa. A matriz dos arenitos conglomeráticos não contém pelitos, que exclui a possibilidade de transporte por fluxo coesivo de detritos, mas torna esta fácies algo distinta dos rain-out diamictites de ambientes glaciomarinhos e glaciolacustres decritos por Eyles \& Eyles (1992). Esta característica pode ser explicada pela influência dos processos costeiros aqui descritos, cuja energia impede a decantação de material pelítico desprendido dos blocos de gelo flutuantes. Outra hipótese é a de deformação plástica de sedimentos inconsolidados, com a mistura de material arenoso e conglomerático inicialmente depositado como camadas bem definidas, o que não exclui a possibilidade de uma origem por chuva de detritos para os níveis conglomeráticos. Vale ressaltar que Pazos et al. (1998) interpretaram esta fácies como 
Tabela 1 - Classificação de litofácies e respectivas características sedimentares da porção inferior da Formação Playa Hermosa. Esquema de fácies modificado de Eyles et al. (1983).

\begin{tabular}{|c|c|c|c|}
\hline $\begin{array}{l}\text { Código } \\
\text { de } \\
\text { Fácies }\end{array}$ & Litofácies & Descrição & Interpretação \\
\hline$G m$ & Conglomerados maciços & $\begin{array}{l}\text { Conglomerados sustentados por clastos com } \\
\text { estrutura maciça. Clastos intraformacionais } \\
\text { freqüentemente contorcidos }\end{array}$ & $\begin{array}{l}\text { Fluxo denso com transporte associado a } \\
\text { fluxo granular comandado por pressão } \\
\text { dispersiva (choque de grãos) }\end{array}$ \\
\hline Spm & Arenitos conglomeráticos & $\begin{array}{l}\text { Arenitos finos e siltitos seixosos (pebble } \\
\text { mudstone/sandstone) geralmente maciços, } \\
\text { com clastos dispersos }\end{array}$ & $\begin{array}{l}\text { Fluxo denso granular. Processo análogo à } \\
\text { chuva de detritos (rain-out sensu Eyles\& } \\
\text { Eyles 1992) responsável pela rápida de } \\
\text { posição por suspensão de material grosso } \\
\text { em meio ao fino }\end{array}$ \\
\hline$S m$ & Arenitos maciços & $\begin{array}{l}\text { Níveis de arenitos grossos, médios a finos, } \\
\text { por vezes até pelitos, maciços, bem selecio- } \\
\text { nados. Níveis de intraclastos residuais (lag) }\end{array}$ & $\begin{array}{l}\text { Fluxos turbulentos arenosos de alta densi- } \\
\text { dade em posição distal aos ruditos das } \\
\text { fácies Gm e Spm, com retrabalhamento por } \\
\text { onda e geração de níveis de seixos residuais }\end{array}$ \\
\hline$S r$ & $\begin{array}{l}\text { Arenitos com laminação } \\
\text { ondulada e lentes pelíticas }\end{array}$ & $\begin{array}{l}\text { Arenitos finos a muito finos e pelitos com la- } \\
\text { minação ondulada e marcas onduladas assi- } \\
\text { métricas e simétricas. Base de camadas } \\
\text { escavada. }\end{array}$ & $\begin{array}{l}\text { Alternância de deposição por tração e } \\
\text { decantação }\end{array}$ \\
\hline$S h$ & $\begin{array}{l}\text { Arenitos com laminação } \\
\text { plano-paralela }\end{array}$ & $\begin{array}{l}\text { Arenitos finos a muito finos com laminação } \\
\text { plano-paralela }\end{array}$ & $\begin{array}{l}\text { Tração de carga de fluxo dirigida por ondas } \\
\text { e / ou por correntes oscilatórias }\end{array}$ \\
\hline Sc & $\begin{array}{l}\text { Arenitos com laminação } \\
\text { convoluta e dropstone }\end{array}$ & $\begin{array}{l}\text { Arenitos finos siltosos com laminação } \\
\text { convoluta e clasto anômalo (dropstone) }\end{array}$ & $\begin{array}{l}\text { Deformações por gelo e presença de clasto } \\
\text { caído de bloco de gelo }\end{array}$ \\
\hline$S d$ & Arenitos com clasto caído & $\begin{array}{l}\text { Arenitos finos a muito finos, siltosos, em } \\
\text { camadas centimétricas de geometria tabular, } \\
\text { deformados com clasto caído }\end{array}$ & $\begin{array}{l}\text { Produto de decantação de material em sus- } \\
\text { pensão. O clasto de tamanho anômalo é } \\
\text { interpretado como caído de blocos de gelo } \\
\text { flutuante }\end{array}$ \\
\hline SH & $\begin{array}{l}\text { Arenitos com estratificações } \\
\text { cruzadas hummocky e swaley }\end{array}$ & $\begin{array}{l}\text { Arenitos finos a médios com estratificações } \\
\text { cruzadas hummocky e swaley, com boa sele- } \\
\text { ção granulométrica. O topo dos estratos } \\
\text { exibe marcas onduladas de perfil simétrico e } \\
\text { assimétrico }\end{array}$ & $\begin{array}{l}\text { As estratificações hummocky e swaley de } \\
\text { fluxo oscilatório ou combinado. Depósitos } \\
\text { gerados por ondas de tempestade em ambi- } \\
\text { ente marinho raso de face litorânea }\end{array}$ \\
\hline$H w$ & Ritmitos heterolíticos & $\begin{array}{l}\text { Finas intercalações heterolíticas }(2-5 \mathrm{~cm} \text { de } \\
\text { espessura) de arenitos finos a muito finos e } \\
\text { siltitos, maciços a laminados }\end{array}$ & $\begin{array}{l}\text { Atuação de ondas de tempo bom na zona de } \\
\text { face litorânea }\end{array}$ \\
\hline$R l$ & Ritmitos laminados & $\begin{array}{l}\text { Intercalações de arenitos finos a muito finos, } \\
\text { silticos a argilosos, maniados, e siltitos } \\
\text { arenosos maciços ou laminação mal definida }\end{array}$ & $\begin{array}{l}\text { Deposição por suspensão de material das } \\
\text { correntes turbulentas devido à uma atenua- } \\
\text { ção da energia destas correntes }\end{array}$ \\
\hline
\end{tabular}
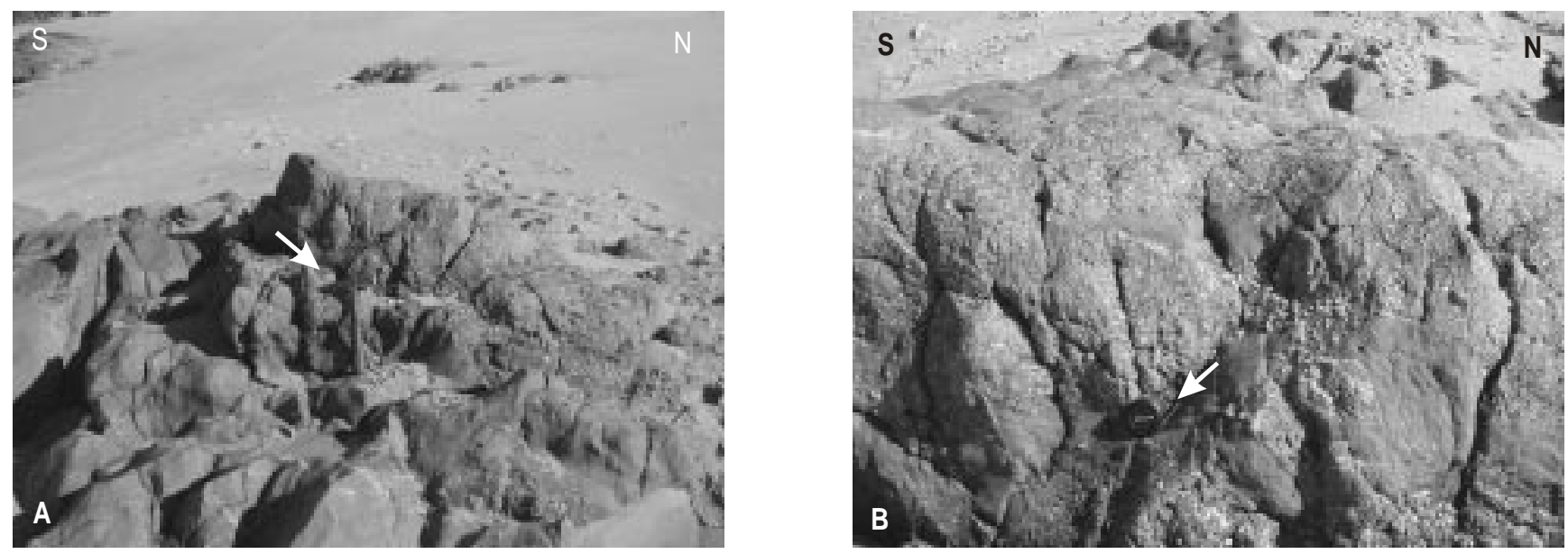

Figura 6- Fácies Spm (arenitos conglomeráticos maciços) de matriz de arenito fino com clastos de quartzito e quartzo. A: Visão geral da Fácies Spm. Martelo como escala mede $41 \mathrm{~cm}$, B: Detalhe da fácies com destaque para clastos denotando processo de chuva de detritos (rain-out sensu Eyles \& Eyles 1992) por desprendimento a partir de blocos de gelo flutuantes (icebergs). Tampa de lente de $3 \mathrm{~cm}$ como escala. Orla de Playa Grande. 
diamictitos maciços ou gradacionais por fluxos subaquosos.

Fácies de Arenitos Maciços (Sm) Compreende níveis de arenitos grossos, médios e finos, bem selecionados, intercalados por vezes a camadas centimétricas de pelitos de aspecto maciço. Estes arenitos encontram-se dispostos em camadas decimétricas cuja espessura oscila entre 15 e $35 \mathrm{~cm}$. A geometria das camadas é tabular, ainda que ocorram níveis ocasionais lenticulares relacionados à Fácies de Arenitos com Marcas Onduladas ( $\mathrm{Sr}$ ). Em determinados estratos observaram-se níveis de clastos residuais (lags) de granulação seixo $(1-3 \mathrm{~cm})$. Esta fácies associa-se subordinadamente aos arenitos com marcas onduladas (Fácies Sr) com os quais mantém contatos bruscos (Fig. 4).

A geração de arenitos maciços é interpretada como deposição por correntes de turbidez de alta densidade (Lowe 1982), sendo o material arenoso depositado diretamente da suspensão turbulenta, ou a partir de transporte não coesivo sustentado pela colisão entre as partículas, sem que ocorra o desenvolvimento de formas de leito. Os arenitos são distais aos ruditos das Fácies $G m$. A presença de níveis com concentração de clastos residuais sugere erosão localizada, possivelmente relacionada a eventos de fluxo oscilatório, com retrabalhamento episódico da Fácies $S m$ e transporte seletivo das frações mais finas.

Fácies de Arenitos com Marcas Onduladas ( $\mathrm{Sr}$ ) Esta fácies é composta por arenitos finos a muito finos e pelitos arenosos dispostos em camadas de até $10 \mathrm{~cm}$ de espessura. Os arenitos apresentam topo ondulado das camadas devido ao cavalgamento supercrítico de marcas onduladas assimétricas e, mais raramente, simétricas. As camadas geralmente apresentam base plana, ocorrendo localmente base irregularmente escavada, e pequenos truncamentos de baixo-ângulo. Localmente ocorre laminação cruzada cavalgante subcrítica (Fig. 7). A ausência de planos confiáveis passíveis de obtenção de medidas de paleofluxo impediram a coleta sistemática de dados de paleocorrentes $3 / 4$ presença de planos em duas dimensões e, para tal, requer-se em três dimensões $3 / 4$, mas o sentido geral inferido sugere paleotransporte para norte (Fig. 7). Os pelitos arenosos possuem laminação mal definida. Ocorrem freqüentemente em ciclos granodecrescentes métricos iniciados por camadas das fácies de Arenitos Maciços (Sm) ou de Conglomerados Maciços $(G m)$. Também associa-se à Fácies de Arenitos com Estratificação Cruzada Swaley e Hummocky $(\mathrm{SH})$ com a qual mantém contatos abruptos.

A Fácies de Arenitos com Laminação Ondulada $(S r)$ é interpretada como o resultado de deposição a partir de correntes unidirecionais ou combinadas (fluxo unidirecional e oscilatório), sendo a preservação das pequenas formas de leito e seu empilhamento em camadas métricas homogêneas atribuída à decantação simultânea de material em suspensão. A laminação ondulada é, portanto, o resultado do cavalgamento de marcas onduladas a altos ângulos, sugerindo grande disponibilidade de material em suspensão. A presença de laminações cruzadas cavalgantes unidirecionais de base reta e perfis assimétricos sugere a ação de correntes unidirecionais, provavelmente relacionadas a correntes de turbidez. A ocorrência de formas simétricas de base escavada, interpretadas como o produto de fluxo oscilatório ou combinado, e sua relação com lags conglomeráticos e arenitos com estratificação cruzada hummocky e swaley, é interpretada como produto da ação de ondas de tempestade que retrabalham o topo dos ciclos granodecrescentes turbidíticos.

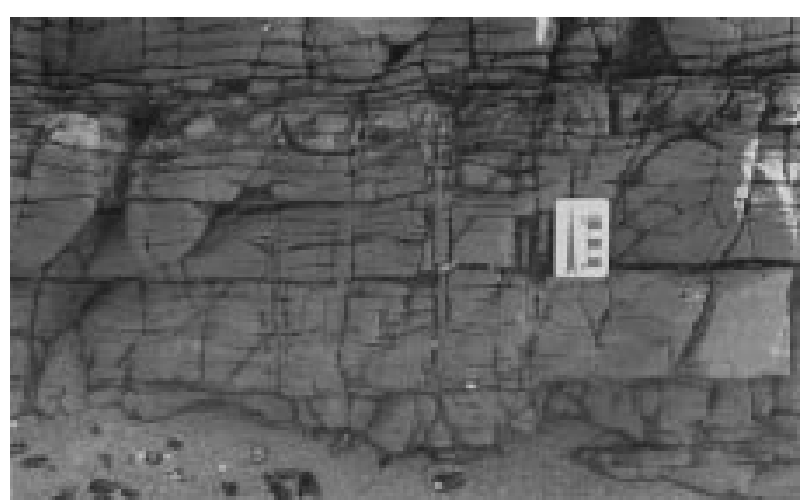

Figura 7- Fácies Sr (arenitos com marcas onduladas) que exibem marcas onduladas de perfil assimétrico com estruturação interna dada por laminações cruzadas cavalgantes supercríticas com sentido de paleocorrente para norte (direita da foto). Notar base plana e pequenos truncamentos de baixo-ângulo. Orla de Playa Hermosa.

Fácies de Arenitos com Laminação Plano-Paralela (Sh) Consiste de arenitos finos a muito finos com laminação plano-paralela conspícua. Por vezes, a laminação não é perfeitamente horizontal, resultando em sutis truncamentos de ângulos baixos $\left(<5^{\circ}\right)$. As camadas têm espessura centimétrica a decimétrica e geometria tabular, ocorrendo geralmente associados com as fácies de Arenitos Maciços $(\mathrm{Sm})$ e Conglomerados Maciços $(\mathrm{Gm})$, sobre estas em ciclos granodecrescentes.

Esta fácies é interpretada como produto de deposição de carga de tração arenosa em leito plano, possivelmente em condições próximas à velocidade crítica de regime de fluxo. Sua associação com fácies interpretadas como deposição direta de material suspenso por correntes turbulentas de alta densidade ( $\mathrm{Gm}$ e $\mathrm{Sm}$ ), sugere origem relacionada à atenuação da energia destas correntes.

Fácies de Arenitos com Laminação Convoluta $(\boldsymbol{S c})$ Consiste de arenitos finos a muito finos, siltosos, em meio a níveis indeformados, dispostos em camadas de espessura decimétrica com geometria tabular, que apresentam deformações na forma de laminações convolutas em dobras com vergência para norte, concordante com o sentido das paleocorrentes das marcas onduladas e laminações cruzadas da Fácies $\operatorname{Sr}$ (Fig. 8).

A ocorrência desta fácies em meio a camadas não deformadas é sugestiva de origem atectônica. A consistência das atitudes do plano axial das dobras, e portanto de sua vergência, aliada à concordância com as paleocorrentes indicadas pelas marcas onduladas, sugere uma origem relacionada ao paleodeclive, provavelmente sob a forma de deslizamentos (slumps).

Fácies de Arenitos Laminados com Clastos Caídos $(S d)$ Compreende arenitos finos a muito finos, siltosos, laminados, dispostos em camadas centimétricas de geometria tabular, que se mostram muito deformados com clastos caídos (Fig. 9), dispostos normalmente de forma isolada. Na Fig. 4 a seção levantada mostra apenas um clasto isolado que foi observado neste trabalho (Figs. 10 e 11). No entanto, outros clastos isolados de menores dimensões ocorrem (Leda Sánchez-Bettucci, comunicação pessoal), especialmente um de quartzito próximo ao de $71 \mathrm{~cm}$ de forma bem arredondada e esférica como uma bola. O clasto isolado das Figuras 10 e 11 possui as seguintes características: (i) tamanho anômalo 


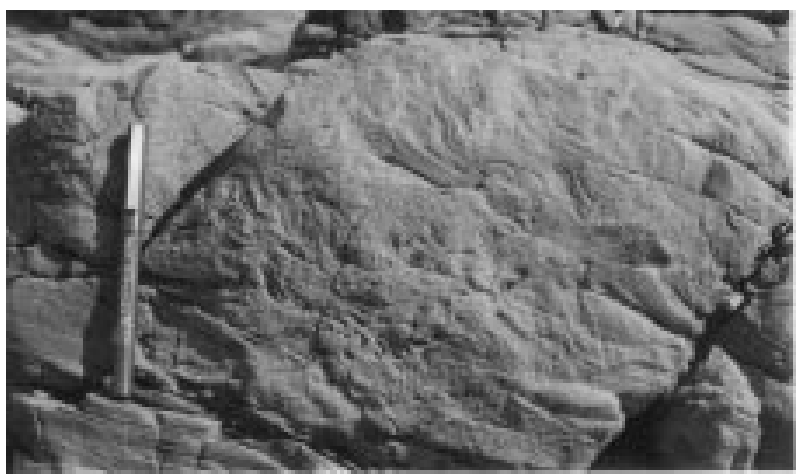

Figura 8 - Arenitos finos a muito finos siltosos da Fácies Sc onde ocorrem deformações na forma de laminações convolutas em dobras com vergência para norte, coerente com o sentido das paleocorrentes das marcas onduladas e das laminações cruzadas cavalgantes. Interpreta-se uma origem vinculada à instabilização do paleodeclive por meio de deslizamentos (slumps). Orla de Playa Hermosa.

mínimo de $71 \mathrm{~cm}$ (matacão), pois se acha fragmentado, indicando que suas dimensões eram maiores, (ii) intenso fraturamento, (iii) forma alongada irregular (prolata) com algumas arestas subarredondadas, (iv) introdução oblíqua no sedimento hospedeiro, (v) ocorrência isolada (lonestone de Frakes \& Francis 1988), (vi) contato basal e lateral do tipo bending and rucking (sensu Thomas \& Connell 1985), conforme já observado por Pazos et al. (1998, 2003), (vii) presença em sedimentos finos mostrando um grande contraste de granulação, (viii) posição ortogonal à laminação e (ix) composição quartzítica. Vale ressaltar que Pazos et al. $(1998,2003)$ reportaram a presença de estrias longitudinais neste clasto isolado (vide Fig. 10).

A fácies como um todo é interpretada como produto de decantação de material em suspensão. O clasto de tamanho anômalo (outsized-clast) pode ser interpretado como um clasto caído (dropstone) após transporte por blocos flutuantes de gelo. A expressiva diferença de granulação entre o clasto e os arenitos finos em que se encontra alojado constitui um paradoxo hidrodinâmico (Bennett et al. 1994, 1996, Bennett \& Doyle 1996), ou seja, um contraste entre a relativa baixa energia responsável pela deposição dos arenitos finos e a alta energia requerida para transportar o matacão de quartzito. A deformação tipo bending and rucking é interpretada como decorrente da própria queda do clasto, que ocasiona uma dobra (bending) pelo impacto no sedimento abaixo e, nos lados do clasto, um dobramento apertado por transporte de sedimento para cima (rucking) (Fig. 11). A ocorrência isolada e a posição oblíqua e ortogonal à laminação dos arenitos, concomitante à deformação do sedimento em torno do clasto isolado, sugere a sua queda, em oposição à origem por fluxo de alta densidade.

Fácies de Arenitos com Estratificações Cruzadas Hummocky e Swaley $(\mathbf{S H})$ Esta fácies consiste de arenitos finos a médios com boa seleção granulométrica, dispostos em camadas decimétricas a métricas, onduladas, com estratificação cruzada tipo hummocky e swaley de amplitude decimétrica e comprimento de onda de até 3 m (Fig. 12). Essas camadas compõem a porção basal de ciclos decimétricos a métricos cujo topo exibe marcas onduladas de perfil simétrico com comprimentos de onda oscilando entre 6 e $10 \mathrm{~cm}$ e cristas de ápice arredondado e, subordinadamente, em cúspide. Ocorrem também marcas onduladas assimétricas assim como laminações cruzadas truncadas por ondas (micro-hummocky, sensu Dott \& Bourgeois 1982) (Fig. 13).

As estratificações cruzadas hummocky e swaley indicam a ação de fluxo oscilatório ou combinado (Cheel \& Leckie 1992), e a passagem desta fácies para estruturas de menor energia (marcas onduladas) em direção ao topo sugere recorrência de eventos episódicos, compondo ciclos do tipo shallowing upward. Essas características são interpretadas como resultado de aporte ou retrabalhamento de material arenoso em eventos de tempestades, em um ambiente marinho raso, de transição entre face litorânea (shoreface) e costa afora (offshore transition), abaixo do limite de ação de ondas de tempo bom, configurando tempestitos.

Fácies de Ritmitos Heterolíticos $(\boldsymbol{H w})$ Esta fácies consiste de intercalações heterolíticas ( $2-5 \mathrm{~cm}$ de espessura) de arenitos finos a muito finos, sílticos a argilosos, maciços a laminados, e siltitos arenosos maciços ou com laminação mal definida. Nos arenitos ocorrem marcas onduladas predominantemente assimétricas e laminação wavy. Estas intercalações formam camadas de vários metros de espessura com geometria aparentemente tabular de grande continuidade lateral.

A ritmicidade evidencia uma alternância de deposição de areia transportada por tração e decantação de material fino (silte), caracterizando aporte episódico de material arenoso em ambiente de baixa energia. O predomínio de marcas onduladas assimétricas sugere transporte por correntes unidirecionais, provavelmente relacionadas a porções distais de depósitos de correntes de turbidez sob influência dos eventos de tempestades.

Fácies de Ritmitos Laminados $(\boldsymbol{R} l)$ Esta fácies compreende intercalações de arenitos finos a muito finos, sílticos a argilosos, laminados, e siltitos arenosos maciços ou com laminação mal definida. Estas intercalações formam camadas decimétricas $(10-15 \mathrm{~cm})$ em ciclos de vários metros de espessura, geometria tabular e continuidade lateral. Ocorrem sobretudo no topo (Fig. 4). Esta fácies é interpretada como resultado de deposição por suspensão de material fino das correntes turbulentas (Fácies $\mathrm{Gm}$ e $\mathrm{Sm}$ ), relacionado à atenuação da energia destas correntes.

\section{INTERPRETAÇÃODOAMBIENTEDEPOSICIONALDAFOR-} MAÇÃO PLAYA HERMOSA As fácies sedimentares da Formação Playa Hermosa sugerem a interação de processos de transporte e sedimentação distintos, em um sistema complexo com influência glacial, ação de correntes de turbidez e de ondas de tempestades.

A influência glacial desses depósitos é denunciada pelo aporte de material areno-rudáceo por chuva de detritos a partir de blocos de gelo flutuantes (rain-out), pelos dados paleomagnéticos (D’Agrella \& Pacca 1988, Sánchez-Bettucci \& Rapalini 1998, 2002) que indicam posição do Cráton Rio de La Plata e regiões vizinhas junto à baixas e médias latitudes no Neoproterozóico (c. $595 \mathrm{Ma})$ e, principalmente, pela presença de clastos isolados (dropstones) em meio a sedimentos finos, indicando paradoxo hidrodinâmico. Tal interpretação é sustentada em parte por Pazos et al. (2003).

A Fácies Spm possui, como característica mais relevante, material areno-rudáceo mal selecionado e irregularmente misturado com arenitos finos, sem qualquer gradação (mixtites de Pazos et al. 2003). A possibilidade de deposição por fluxos coesivos de detritos é descartada pela falta de pelitos na matriz dos arenitos. Assim, duas hipóteses podem ser sugeridas para a origem desta fácies: (i) deformação penecontemporânea obliterando uma 


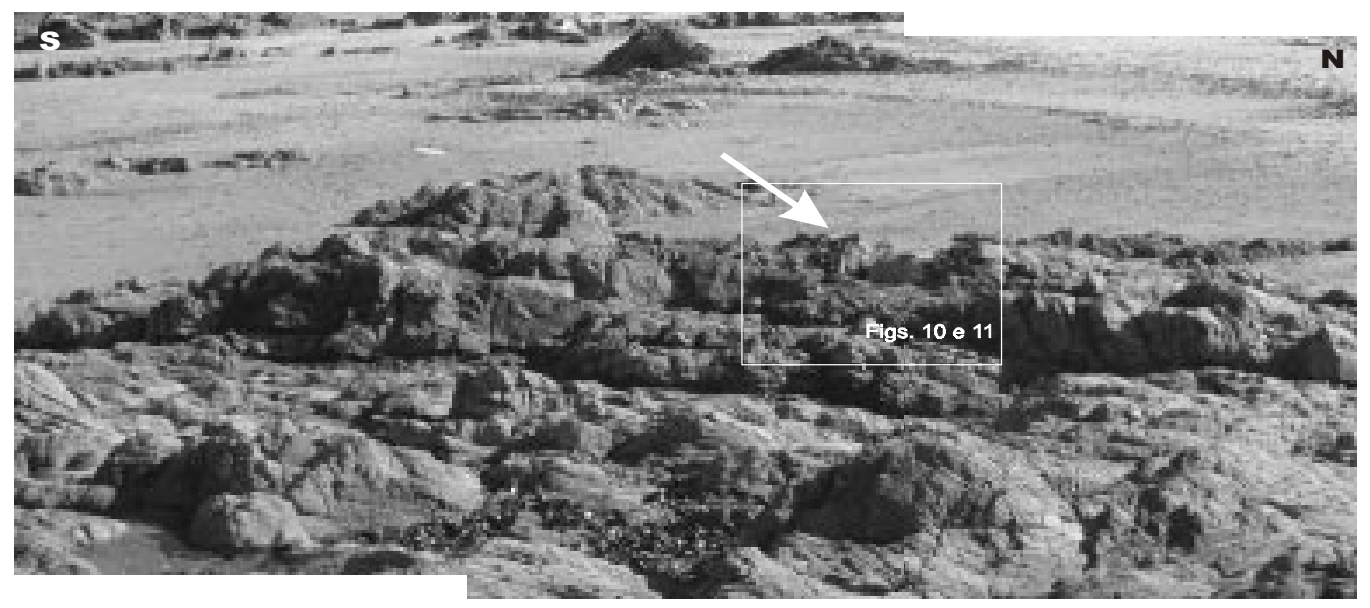

Figura 9 - Fácies de arenitos finos com clasto de tamanho anômalo (Fácies Sd) interpretado como clasto caído (dropstone). Na figura atentar para martelo de $41 \mathrm{~cm}$ como escala (ver seta) e para a localização das figuras 10 e 11 . Orla de Playa Hermosa.
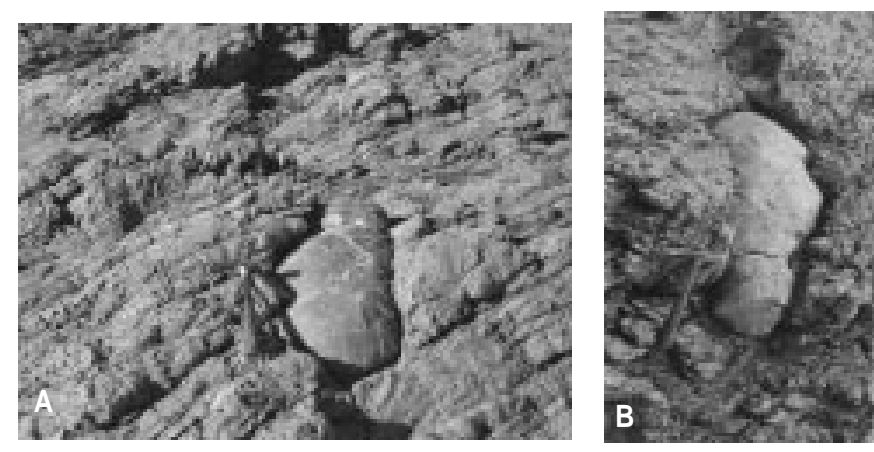

Figura 10 - Fácies Sd (arenitos finos com clasto caído). Dois aspectos do clasto de tamanho anômalo de quartzito de $71 \mathrm{~cm}$ de eixo maior. A: Vista em planta das fraturas, estrias e a forma arredondada do clasto, B: Detalhe do clasto com destaque para deformações tipo bending e rucking (sensu Thomas \& Connell 1985). Martelo de $41 \mathrm{~cm}$ como escala. Orla de Playa Hermosa.

possível organização original em estratos de arenitos finos e de arenitos conglomeráticos com seixos; (ii) deposição de material desprendido de blocos de gelo flutuantes, em processos análogos aos interpretados para os rain-out diamictites de Eyles \& Eyles (1992), porém com ausência de fração fina pela influência de processos costeiros, cuja energia impede a decantação de pelitos. Evidências adicionais da presença de blocos de gelo flutuantes quanto de episódios de retrabalhamento por ondas favorecem a hipótese de chuva de detritos.

A principal evidência de atividade glacial é a presença da Fácies $S d$ (arenitos finos laminados com clastos caídos). É geralmente aceito que clastos isolados em sedimentos finos sejam formados por queda a partir de blocos de gelo flutuantes (icebergs) e constituam dropstones (clastos caídos), estabelecendo uma evidência direta da presença de remanescentes de gelo polar e, por conseqüência, de atividade glacial (e.g. Herman \& Hopkins 1980, Spjeldnaes 1981, Thomas \& Connell 1985, Frakes \& Francis 1988, Gilbert 1990, Francis \& Frakes 1993, Bennett \& Doyle 1996). Segundo Bennett et al. (1994, 1996) e Bennett \& Doyle (1996), um dropstone pode ser definido como clasto de tamanho e/ou composição litológica anômala, com evidências de introdução vertical
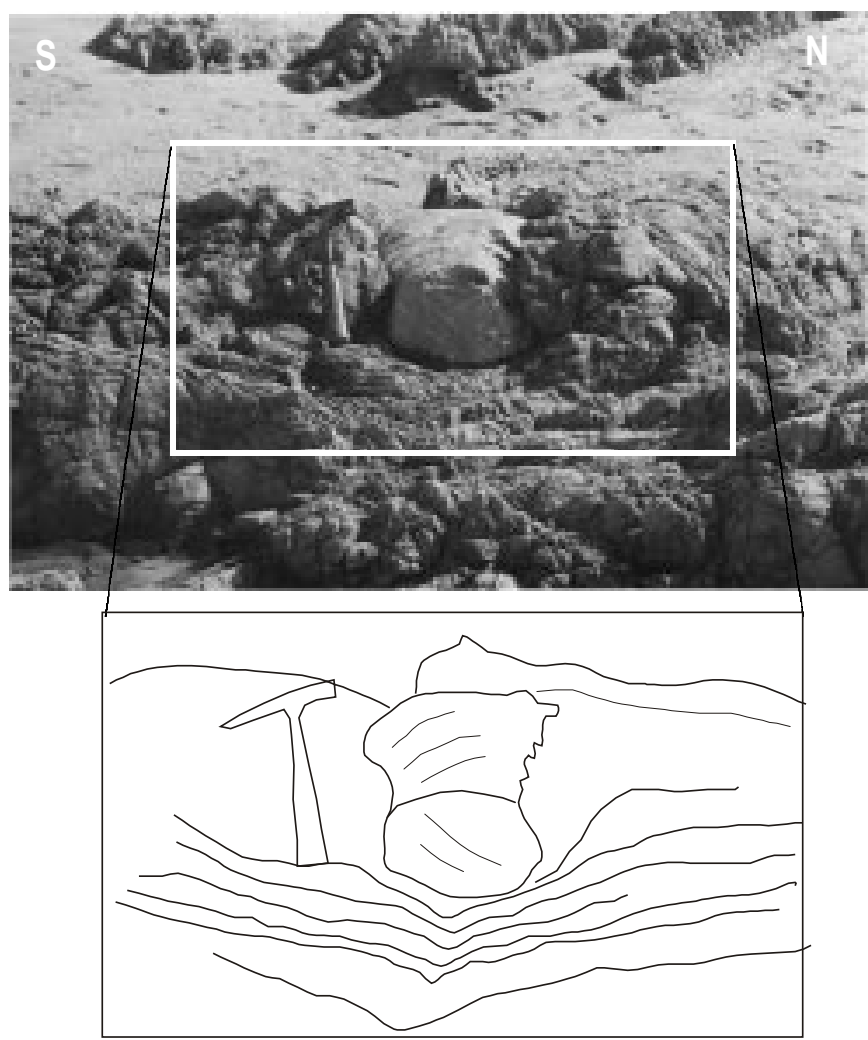

Figura 11 - Detalhe do clasto caído com destaque para deformações tipo bending e rucking (sensu Thomas \& Connell 1985). Atentar para a posição oblíqua em relação às camadas e a forma alongada irregular com arestas arredondadas. Martelo como escala mede $41 \mathrm{~cm}$. Orla de Playa Hermosa.

no sedimento hospedeiro de granulação menor, denotando paradoxo hidrodinâmico. Entretanto, muitas vezes esse não parece ser o único mecanismo de origem para clastos isolados.

Bennett et al. (1996) reconheceram quatro processos principais de transporte e deposição de clastos isolados, a saber: (i) carreamento pelo gelo através de icebergs (ice rafting), (ii) projéteis 


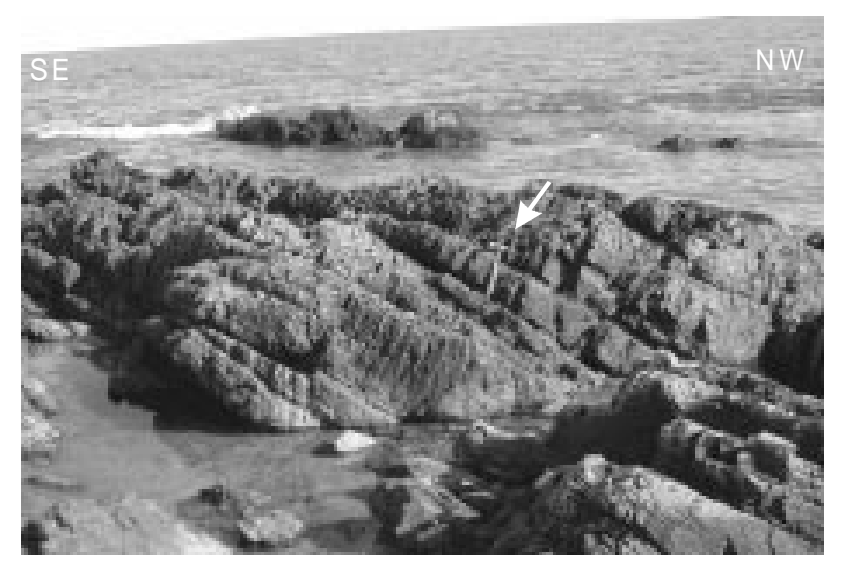

Figura 12 - Arenitos com Estratificações Cruzadas Hummockye Swaley (Fácies SH). Notar truncamentos de baixo-ângulo e amplitude de onda das estratificações de até $3 \mathrm{~m}$. Martelo de escala no centro da foto mede $41 \mathrm{~cm}$. Orla de Playa Hermosa.

impulsionados por erupções vulcânicas, (iii) transporte biológico e (iv) processos gravitacionais. Em razão da idade dos sedimentos da Formação Playa Hermosa, descarta-se a hipótese de transporte biológico do clasto anômalo (biological rafting), haja vista a ausência de vegetação terrestre no Neoproterozóico, ou de grandes algas flutuantes desprendidas do substrato (Shumway 1953, Emery 1965, Bennett et al. 1996), registradas somente a partir do Devoniano. Também a hipótese balística para o clasto isolado (projétil vulcânico) de Playa Hermosa deve ser eliminada em decorrência da composição litológica do clasto (quartzito) e de sua forma arredondada.

O transporte de clastos anômalos por processos gravitacionais seria compatível com a presença de depósitos de correntes de turbidez na Formação Playa Hermosa. As principais características e os mecanismos do transporte de clastos anômalos e posterior deposição por correntes de turbidez estão descritos em Postma et al. (1988). Fragmentos sedimentados desse modo normalmente ocorrem em concentrações de calhaus e até matacões e estão, necessariamente, associados com marcas de arrasto e escavação, sedimentos gradacionais e outras estruturas de transporte do clasto por fluxo denso. Como apontado por Donovan \& Pickerill (1997), são de relevância particular os denominados outrunner blocks (Prior et al. 1982) que consistem de megaclastos isolados (até $5 \mathrm{~m}$ em diâmetro) em fluxos de massa submarinos. Tais blocos são deslocados por inércia para além da área de deposição da maior parte do material rudítico de um fluxo denso, sendo transportados como carga de fundo por distâncias de até $1 \mathrm{~km}$ até sua deposição junto a material de granulação consideravelmente menor. Segundo Donovan \& Pickerill (1997) os grandes clastos costumam, em sua passagem, deixar impressas marcas de arrasto e de impacto durante o transporte. Ademais, o eixo maior dos megaclastos costumeiramente posiciona-se paralelo à estratificação dos sedimentos, coerente com transporte como carga de fundo. As características do clasto encontrado em sedimentos da Formação Playa Hermosa são contrárias às expostas, não havendo evidências de transporte por arrasto ou rolamento, mas de introdução vertical, como sugere sua posição oblíqua ao plano de estratificação e a deformação das camadas inferiores e laterais. Isto desfavorece a hipótese de deposição do clasto anômalo por correntes de turbidez.

Assim, resta a opção mais provável de origem do clasto isolado
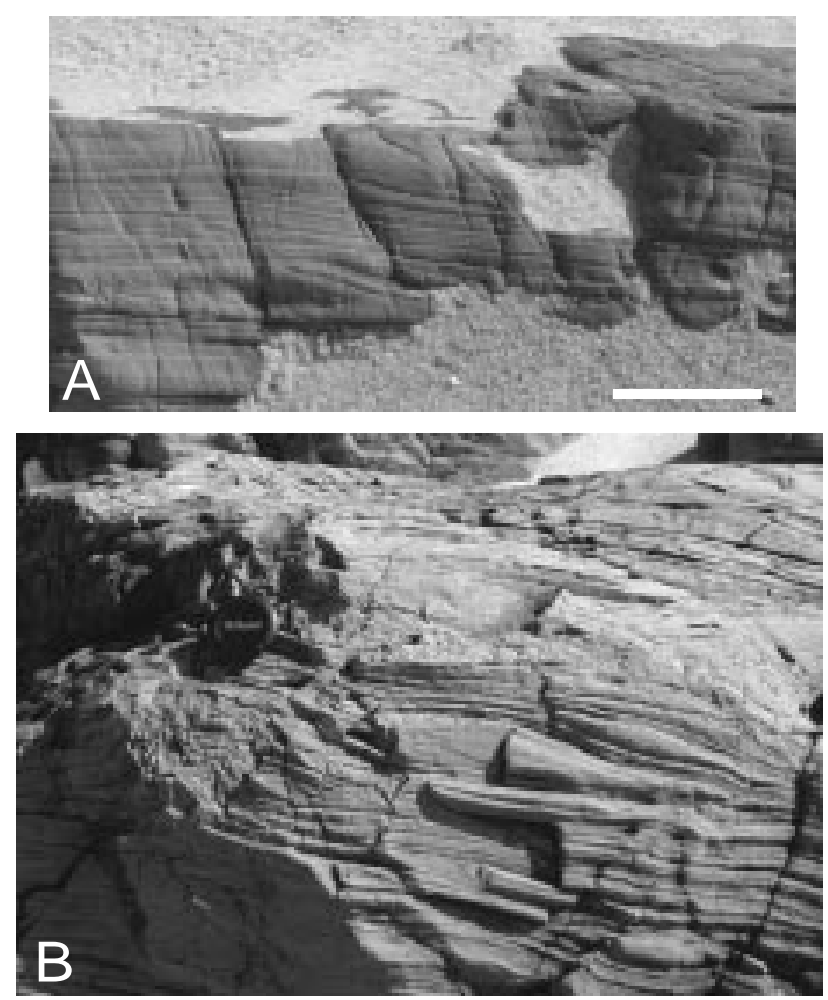

Figura 13 - Fácies de Arenitos com Estratificações Cruzadas Hummocky e Swaley (Fácies SH). Nas fotos destacam-se arenitos finos com estratificações cruzadas micro-hummocky $(A e B) e$, em A, também se nota estratificação cruzada tipo swaley. Em A barra de $20 \mathrm{~cm}$ como escala, e em B, tampa de lente com $3 \mathrm{~cm}$. Orla de Playa Hermosa.

de Playa Hermosa por carreamento pelo gelo (ice rafting), conforme sugerido preliminarmente por Pazos et al. (1998) e reiterado em Pazos et al. (2003). De fato, o tamanho anômalo, a ocorrência isolada (lonestone), a posição oblíqua, a ocorrência de estruturas deformacionais tipo bending e rucking (sensu Thomas \& Connell 1985, Fig. 11) e a colocação dentro de sedimentos finos (paradoxo hidrodinâmico), sugerem uma origem por queda a partir de blocos de gelo flutuantes.

Por outro lado, dados paleomagnéticos recentes coletados em 6 amostras da Formação Playa Hermosa (Sánchez-Bettucci \& Rapalini 1998, 2002) indicam que houve deslocamento do Cráton Rio de La Plata e áreas adjacentes e, conseqüentemente, da Formação Playa Hermosa para latitudes intermediárias e baixas no encerramento do Neoproterozóico (c. 590 Ma). Isso mostra que as reconstruções paleogeográficas com base em dados paleomagnéticos indicam que esta formação situou-se relativamente próxima ao pólo terrestre, a baixas e médias latitudes.

A maior parte da sucessão estudada é composta por fácies interpretadas como produtos de correntes de turbidez, como reconhecido por Masquelin \& Sánchez-Bettucci (1993) e SánchezBettucci \& Pazos (1996), possivelmente relacionadas a grande aporte sedimentar em ambiente glaciomarinho ou glaciolacustre com geleiras proximais (e.g. Eyles \& Eyles 1992, Eyles 1993).

Estruturas de ação episódica de fluxo oscilatório (Fácies $S H$ ) indicam eventos de tempestades que retrabalharam turbiditos em profundidade abaixo da ação de ondas de tempo bom, constituin- 
do tempestitos (sensu Seilacher 1982). A ocorrência de tais eventos evidencia corpo d'água de grandes dimensões com ampla área de geração das oscilações (fetch). As evidências favorecem um ambiente glaciomarinho, mas não se descarta um ambiente de grandes lagos de degelo.

IDADEECORRELAÇÕESREGIONAIS Aformadeocorrência e as relações de campo da Formação Playa Hermosa — pequena área isolada e restrita à costa, mantendo contato apenas com corpos sub-vulcânicos da Suíte Sierra de Animas (£570 Ma)— permitem apenas defini-la como pré-cambriana. Outras características - litologias, estruturas, deformações sin- e pós-deposicionais etc- - apresentam similaridades e distinções com as de várias unidades pré-cambrianas do Uruguai, não permitindo, portanto, correlação satisfatória com nenhuma. Como exemplo, apresenta depósitos marinhos rasos afetados por tempestades similares àqueles do Grupo Rocha no balneário Faro de La Paloma; distintamente, é menos deformado e não apresenta metamorfismo, assemelhando-se, nestes aspectos, à Formação Piedras de Afilar, litologicamente mais variada (vide Fragoso-Cesar et al. 1987).

Masquelin \& Sánchez-Bettucci (1993) correlacionaram a sucessão exposta em Playa Hermosa com a Formação Arroio dos Nobres (sensu Ribeiro et al. 1966) da Bacia do Camaquã no RS. Todavia, trabalhos desenvolvidos nesta bacia (Fragoso-Cesar et al. 2000, Pelosi \& Fragoso-Cesar em prep., Janikian et al. em prep.) vêm demostrando que a sedimentação do Grupo Camaquã (sensu Fragoso-Cesar et al. 2000) constituído pelas formações Maricá, basal, siliciclástica de ambientes marinho-aluviais, Crespos, vulcano-sedimentar e Santa Bárbara, eminentemente siliciclástica gerada em ambientes marinho e aluvial, não apresenta indícios de influência glacial. Por outro lado, o Grupo Camaquã, à luz dos dados geocronológicos disponíveis, foi gerado entre $620 \mathrm{Ma}$ (idade mínima do embasamento da Formação Maricá de acordo com Soliani Jr. 1986) e $535 \pm 16 \mathrm{Ma}$ (valor referente a datações K/Ar na fração fina da unidade inferior da região das Minas do Camaquã de Bonhomme \& Ribeiro 1983). A Formação Maricá poderia ser correlata à Formação Playa Hermosa, pois se situa abaixo do vulcanismo da Formação Crespos, possível equivalente da Suíte Sierra de Animas. No entanto, as evidências indicam que a deposição ocorreu em ambiente aluvial e marinho raso (Pelosi \& Fragoso-Cesar em prep.). Assim, descartam-se diante do exposto correlações entre a Formação Playa Hermosa e unidades do Grupo Camaquã no RS, a despeito de uma possível evolução contemporânea. Em trabalho recente, Fambrini et al. (2002) apontam que a Formação Barriga Negra (sensu Fragoso-Cesar et al. 1987) é a única possivelmente correlata ao Grupo Camaquã.

A única característica distintiva da Formação Playa Hermosa evidências de influência glacial - só é também reconhecida em depósitos pré-cambrianos a norte do paralelo 22, a mais de 1500 $\mathrm{km}$ de distância (e.g. Formação Jequitai e Grupo Macaúbas em Minas Gerais, Formação Puga no Mato Grosso; Karfunkel \& Hoppe 1988, Alvarenga \& Trompette 1992, Boggiani 1997), registros de glaciação neoproterozóica no Brasil. Se o evento glacial foi ou não o mesmo, somente estudos geocronológicos da Formação Playa
Hermosa permitirão elucidar esta hipótese.

CONSIDERAÇÕES FINAIS A Formação Playa Hermosa é redefinida neste trabalho. Nesta proposição, excluem-se as manifestações vulcânicas do topo e depósitos relacionados (e.g. conglomerados com fonte vulcânica) que pertenceriam à Suíte Sierra de Animas. Deste modo, esta unidade compreende tão somente depósitos siliciclásticos.

A Formação Playa Hermosa representa depósitos gerados por correntes de turbidez com influência glacial que foram afetados por ondas de tempestade em contexto de águas rasas. O caráter glaciogênico desses depósitos é evidenciado pela (i) presença de clasto isolado de tamanho anômalo em arenitos finos a muito finos, interpretado como clasto caído (dropstone), que representa paradoxo hidrodinâmico entre a energia necessária para transportálo e a baixa energia dos sedimentos finos que o alojaram, (ii) Fácies de Arenitos Conglomeráticos Maciços formados por chuva de detritos, processo análogo aos rain-out deposits de Eyles \& Eyles (1992) e (iii) posição da sucessão siliciclástica em latitudes intermediárias e baixas. O clasto isolado foi interpretado como clasto caído devido às suas características intrínsecas (e.g. tamanho anômalo, paradoxo hidrodinâmico), inclusive pelo modo de introdução obliqua nos arenitos finos que o alojaram, o que desfavorece origem por fluxo gravitacional de alta densidade, no qual esperarse-ia um alinhamento segundo a corrente do fluxo. Vale ressaltar que outras formas de transporte da clastos são aqui descartadas (e.g. transporte orgânico). A ação de ondas de tempestades (tempestitos) na Formação Playa Hermosa é indicada por abundantes laminações onduladas e, sobretudo, estratificações cruzadas hummocky, swaley e micro-hummocky presentes no seu topo, sugestivas de lâmina d'água pouco profunda. A ausência de fósseis na Formação Playa Hermosa não permite definir se o ambiente de deposição foi marinho ou lacustre. Entretanto, as estratificações cruzadas hummocky e swaley, interpretadas como resultado de aporte ou retrabalhamento de material arenoso durante tempestades sugerem ambiente marinho raso, de transição entre face litorânea (shoreface) e costa afora (offshore transition), abaixo do limite de ação de ondas de tempo bom. A boa seleção granulométrica dos arenitos sugere ação marinha, mas não se descarta a hipótese de um grande corpo d'água lacustre ter sido o sítio deposicional dos sedimentos da Formação Playa Hermosa.

As características litológicas, paleoambientais e de contexto tectônico da Formação Playa Hermosa impossibilitam a correlação direta com unidades do Grupo Camaquã (RS, Brasil), devendo provavelmente ser mais antiga.

Agradecimentos À FAPESP pelo suporte financeiro (Processos 98/04510-1, 98/03682-3 e 98/11544-0), CNPq (303910/86-0) e à Universidad de la Republica Oriental del Uruguay pela infra-estrutura de campo. Ao Prof. Dr. Thomas R. Fairchild pela revisão e correção do Abstract. Ao Prof. Afonso Cesar R. Nogueira pelas discussões e sugestões, à Profa. Dra. Leda Sánchez-Bettucci pelas sugestões ao texto final e auxílio nos trabalhos de campo. Aos revisores da RBG pelas sugestões ao original.

\section{Referências}

Alvarenga C. J. S. \& Trompette R. 1992. Glacially-influenced sedimentation in the late Proterozoic of Paraguai belt (Mato Grosso, Brasil). Palaeogeo. Palaeoclim. Palaeoecol., 92:85-105.
Bennett M.R. \& Doyle P. 1996. Global cooling inferred from dropstones in the Cretaceous: fact or wishful thinking? Terra Nova, 8:182-185.

Bennett M.R., Doyle P., Mather A.E., Woodfin J.L. 1994. Testing the 
climatic significance of dropstones: an example from southeast Spain. Geol. Mag., 131:845-848.

Bennett M.R., Doyle P., Mather A.E. 1996. Dropstones: their origin and significance. Palaeogeo. Palaeoclim. Palaeoeco., 121:331-339.

Bonhomme M.E. \& Ribeiro M.J. 1983. Datações K-Ar das argilas associadas a mineralizações de cobre da Mina Camaquã e de suas encaixantes. In: SBG, Simpósio Sul-brasileiro de Geologia, 1, Porto Alegre, 1983. Atas, 1:82-88.

Boggiani P.C. 1997. Análise estratigráfica da Bacia Corumbá (Neoproterozóico) - Mato Grosso do Sul. Instituto de Geociências, Universidade de São Paulo, Tese de Doutoramento, 181 p.

Bossi J., Cingolani C., Lambias E., Varela R., Campal N. 1993. Características del magmatismo post-orogénico finibrasiliano en el Uruguay: Formaciones Sierra de Rios e Sierra de Animas. Rev. Bras. Geoc. 23:282-288.

Bossi J., Ferrando L., Fernandez A., Elizalde G., Morales H., Ledesma J.J., Carballo E., Medina E., Ford J., Montaña J. 1975. Carta Geológica del Uruguay (1:1000.000). Dirección de Suelos y Fertilizantes, Ministerio de Agronomia y Pescaderia. Montevideo, Uruguay.

Caputo M.V. \& Crowell J.C. 1985. Migration of glacial centers across Gondwana during Paleozoic Era. GSA Bullettin, 96:1020-1036.

Caorsi, J. \& Goñi, J. C. 1958. Geologia Uruguaya. Instituto Geológico del Uruguay. Bol. 37. Montevideo, Uruguay.

Cheel R.J. \& Leckie D.A. 1992. Coarse-grained storm beds of the Upper Cretaceous Chungo Member (Wapiabi Formation), southern Alberta, Canada. J. Sed. Pet., 62:933-945.

Cingolani C., Llambias E., Varela R., Campal N., Bossi J. 1993. Avances sobre la cronoestratigrafía del magmatismo no-orogénico finibrasiliano en el Uruguay: Formaciones Sierra de Animas y Sierra de Ríos. In: Simposio Internacional del Neoproterozoico-Cámbrico de la Cuenca del Plata, 1, Actas de Resúmenes Extensos, Montevideo, II: 63-68.

D'Agrella M.S.F. \& Pacca I.G. 1988. Paleomagnetism of the Itajai, Castro and Bom Jardim Groups from southern Brazil. Geoph. Jour. 93:365-376.

De Raaf J.F.M., Boersma J.R., van Gelder A. 1977. Wave-generated structures and sequences from a shallow marine succession, Lower Carboniferous, County Cork, Ireland. Sedimentology, 24:451-483.

Donovan S.K. \& Pickerill R.K. 1997. Dropstones: their origin and significance: a comment. Palaeogeo. Palaeoclim. Palaeoeco., 131:175178.

Dott Jr. R.H. \& Bourgeois J. 1982. Hummocky stratification: significance of its variable sequences. GSA Bull., 93:663-680.

Duke W.L 1990. Geostrophic circulation or shallow marine turbidites? The dilemma of paleoflow patterns in storm-influenced prograding shoreline systems: J. Sed. Pet., 60:870-883.

Emery K.O. 1965. Organic transportation of marine sediments. In: Hill M.N. (Editor) The Sea. New York,Wiley, 776-793.

Eyles C.H. 1988. Glacially- and tidally-influenced shallow marine sedimentation of the Late Precambrian Port Askaig Formation, Scotland. Palaeogeo. Palaeoclim. Palaeoeco., 68:73-98.

Eyles C.H. \& Eyles N. 1984. Glaciomarine sediments of the Isle of Man as a key to late Pleistocene stratigraphic investigations in the Irish Sea Basin. Geology, 12:359-364.

Eyles C.H., Eyles N., França A.B. 1993. Glaciation and tectonics in an active intracratonic basin: the Late Palaeozoic Itararé Group, Paraná Basin, Brazil. Sedimentology, 40:1-25.

Eyles C.H., Eyles N., Gostin V.A. 1998. Facies and allostratigraphy of high-latitude, glacially-influenced marine strata of the Early Permian southern Sydney Basin, Australia. Sedimentology, 45:121-161.
Eyles C.H., Eyles N., Miall A.D. 1985. Models of glacio-marine sedimentation and their application to the interpretation of ancient glacial sequences. Palaeogeo. Palaeoclim. Palaeoeco., 51:15-84.

Eyles N. 1990. Late Precambrian "tillites" of the Avalonian-Cadomian belt: marine debris flows in an active tectonic setting. Palaeogeo. Palaeoclim. Palaeoeco., 79:73-98.

Eyles N. 1993. Earth glacial record. Earth Sci. Rev., 35:1-248.

Eyles N. \& Eyles C.H. 1989. Glacially-influenced deep-marine sedimentation of the Late Precambrian Gaskiers Formation, Newfoundland, Canada. Sedimentology, 36:601-620.

Eyles N. \& Eyles C.H. 1992. Glacial depositional systems. In: R.G. Walker \& N.P. James N.P. (eds.) Fácies models. Response to sea level changes. Geological Association of Canada, 73-100.

Eyles N., Eyles C.H., Miall A.D. 1983. Lithofacies types and vertical profile models: an alternative approach to the description and environmental interpretation of glacial diamict and diamictite sequences. Sedimentology, 30:393-410.

Eyles N. \& McCabe A.M. 1989. Glaciomarine facies within subglacial tunnel valleys; the sedimentary record of glacioisostatic downwarping in the Irish Sea Basin. Sedimentology, 36:431-448.

Eyles N. \& Young G. 1993. Geodynamics controls on glaciation in Earth history. In: Deynoux et al. (eds.) Earth Glacial Record. International Geological Correlation Project 260. Cambridge University Press, 127.

Fambrini G.L., Fragoso-Cesar A.R.S., Paes-de-Almeida R., Riccomini C. 2002. A Formação Barriga Negra, Uruguai: possível correlato da Formação Santa Bárbara (Neoproterozóico III-Cambriano?). In:SBG, Congresso brasileiro de geologia, 41, João Pessoa, 2002. Anais, 660.

Fragoso-Cesar A.R.S. 1980. O Craton Rio de La Plata e o Cinturão Dom Feliciano no Escudo Uruguaio-Sul-Riograndense. In: SBG, Congr. Bras. Geol., 31, Camboriú, 1980. Anais, 5:2879-2892.

Fragoso-Cesar A.R.S. 1990. Tectônica de Placas no Bloco São Gabriel (RS) em base nos dados geológicos, geocronológicos e geoquímicos. In: SBGq/IG-USP, Workshop Geoquímica isotópica e litoquímica das regiões Sul e Sudeste do Brasil, São Paulo, SP, Boletim de Resumos, 8-16.

Fragoso-Cesar A.R.S. 1991. Tectônica de Placas no Ciclo Brasiliano: as orogenias dos Cinturões Dom Feliciano e Ribeira no Rio Grande do Sul. Instituto de Geociências, Universidade de São Paulo, São Paulo, Tese de Doutoramento, $366 \mathrm{p}$.

Fragoso-Cesar A.R.S., Fambrini G.L., Paes de Almeida R., Pelosi A.P.M.R., Janikian L., Riccomini C., Machado R., Nogueira A.C.R., Saes G.S. 2000. The Camaquã extensional basin: Neoproterozoic to early Cambrian sequences in southernmost Brazil. Rev. Bras. Geoc., 30:438-441.

Fragoso-Cesar A.R.S., Machado R., Rifas C.G. 1987. Observações sobre o Cinturão Dom Feliciano no Escudo Uruguaio e correlações com o Escudo do Rio Grande do Sul. In: SBG, Simpósio sul-brasileiro de geologia, 3, Atas 2:791-809.

Frakes L.A. \& Francis J.E. 1988. A guide to Phanerozoic cold polar climates from high-latitude ice rafting in the Cretaceous. Nature, 333:547-549.

Francis J.E. \& Frakes L.A. 1993. Cretaceous climates. In: V.P. Wright V.P. (ed.) Sedimentology Review, 1, Blackwell, Oxford, 17-30.

Gesicki A.L.D., Riccomini C, Boggiani P.C. 2002. Ice flow direction during late Paleozoic glaciation in western Paraná Basin, Brazil. $J$. South Am. Earth Sci., 14:933-939.

Gilbert R. 1990. Rafting in glacimarine environments. In: J.A. Dowdeswell \& J.D. Scourse (eds.) Glacimarine Environments: Processes and Sediments. Geological Society Special Publication, 53:105-120. 
Hambrey M.J. \& Harland W.B. 1985. The Late Proterozoic Glaciar Era. Palaeogeo. Palaeoclim. Palaeoeco., 51:255-272.

Harms J.C., Southard J.B., Spearing D.R., Walker R.G. 1975. Depositional environments as interpreted from primary sedimentary structures and stratification sequences. SEPM Short Course n. 2, 161 p. (Society of Economic Paleontologists and Mineralogists).

Herman Y. \& Hopkins D..M. 1980. Arctic oceanic climate in Late Cenozoic times. Science, 209(4456):557-562.

Hoffman P.F., Kaufman A. J., Halverson G. P., Schrag D.P. 1998. A Neoproterozoic Snowball Earth. Science, 281: 1342-1346.

Hoffman P.F. \& Shrag D.P. 2000. Snowball Earth. Scientific American website, issue 100 .

Hyde W.T., Crowley T.J., Baum S.K, Peltler W.R. 2000. Neoproterozoic "snowball Earth" simulations with a coupled climate/ice-sheet model. Nature, 405: 425-429.

Janikian L., Paes-de-Almeida R., Fragoso-Cesar A.R.S., Fambrini G.L. em prep. Redefinição do Grupo Bom Jardim (Neoproterozóico III) em sua área-tipo: litoestratigrafia, paleogeografia e significado tectônico das sucessões vulcano-sedimentares do Supergrupo Camaquã, RS. Rev. Bras. Geoc. (admitido para publicação).

Karfunkel J. \& Hoppe A. 1988. Late Proterozoic glaciation in centraleastern Brazil: synthesis and model. Palaeogeo. Palaeoclim. Palaeoeco., 65:1-21.

Lowe D.R. 1982. Sediment gravity flows: II. Depositional models with special reference to the deposits of high-density turbidity currents. J. Sed. Pet., 52:279-297.

Masquelin H. \& Sánchez-Bettucci L. 1993. Propuesta de evolución tectono-sedimentaria para la Cuenca de Piriápolis, Uruguay. Rev.Bras. Geoc., 23:313-322.

McCabe A.M. 1986. Glaciomarine facies deposited by retreating tidewater glaciers - an example from the Late Pleistocene of Northern Ireland. J. Sed. Pet., 56:880-894.

Miall A.D. 1978. Lithofacies types and vertical profile models in braidedrivers deposits: a summary. In: A.D. Miall (ed.) Fluvial Sedimentology. Calgary, Canadian Society of Petroleum Geologists, Memoir 5 , p. 597-604.

Miall A.D. 1983. Glaciomarine sedimentation in the Gowganda Formation (Huronian), northern Ontario. J. Sed. Pet., 53:477-491.

Miall A.D. 2000. Principles of sedimentary basin analysis. $3^{\text {rd }}$ ed., New York, Springer-Verlag, $616 \mathrm{p}$.

O'Brien P.E. 1989. Subglacial sedimentary features in Late Paleozoic sedimentary rocks, central Victoria, Australia. Sedim. Geol., 61:1-15.

Pazos P.J., Tófalo R.O., Sánchez-Bettucci L. 1998. Procesos sedimentarios e indicadores paleoclimáticos en la sección inferior de la Formación Playa Hermosa, Cuenca Playa Verde, Piriápolis, Uruguay. In SUG/ Facultad de Ciencias, Congresso Uruguayo de Geología, 2, Punta del Este, 1998. Actas, 64-69.

Pazos P.J., Sánchez-Bettucci L, Tófalo R.O. 2003. The Record of the Varanger Glaciation at the Río de La Plata Craton, Vendian-Cambrian of Uruguay. Gondw. Res., 6:65-77.

Pelosi A.P.M.R. \& Fragoso-Cesar A.R.S. em prep. Considerações estratigráficas e paleoambientais da Formação Maricá (Neoproterozóico III), Rio Grande do Sul, Brasil. Rev. Bras. Geoc. (admitido para publicação).

Postma G., Nemec W., Kleinspehn K.L. 1988. Large floating clasts in turbidites: a mechanism for their emplacemement. Sed. Geol., 58:4761.

Preciozzi F.P., Spoturno J., Heizen W., Rossi P. 1985. Carta geológica

\section{del Uruguai a escala 1/500.000. DINAMIGE.}

Prior D.B., Coleman J.M., Bornhold B.D. 1982. Results of a known seafloor instability event. Geo-Marine Letters, 2:117-122.

Ribeiro M., Bocchi P. R., Figueiredo Filho P. M., Tessari R.I. 1966. Geologia da Quadrícula de Caçapava do Sul, Rio Grande do Sul. Rio de Janeiro, DNPM/DFPM, 232 p. (Boletim 127).

Rocha-Campos A.C., Santos P.R. dos, Canuto J.R. 2000. Late Paleozoic glaciotectonic structures in northern Paraná Basin, Brazil. Sed. Geol., 135:131-143.

Sánchez-Bettucci L. 1998. Evolución tectónica del cinturón Dom Feliciano en la región Minas-Piriápolis, República Oriental del Uruguay. Universidad de Buenos Aires, Buenos Aires, Tesis de Doctorado, $344 \mathrm{p}$.

Sánchez-Bettucci L. \& Linares E. 1996. Primeras edades Potasio-Argón en basaltos del Complejo Sierra de las Animas, Uruguay. In: Congr. Geol. Argentino, 13 y Congr. Explor. Hidrocarburos, 3, Actas, I:399-404.

Sánchez-Bettucci L. \& Pazos P. 1996. Análisis paleoambiental y marco tectónico en la Cuenca Playa Verde, Piriápolis, Uruguay. In: Congr. Geol. Argentino, 13, y Congr. Explor. Hidrocarburos, 3, Actas, I: 405-412.

Sánchez-Bettucci L. \& Rapalini A.E. 1998. La curva de desplazamiento polar aparente neopaleozoica del craton Rio de La Plata In: SUG/ Facultad de Ciencias, Congr. Uruguayo Geol., 2, Punta del Este, 1998. Actas, p. 14-15.

Sánchez-Bettucci L. \& Rapalini A.E. 2002. Paleomagnetism of the Sierra de Las Animas Complex, southern Uruguay: its implications in the assembly of western Gondwana. Prec. Res., 118:243-265.

Seilacher A. 1982. Distinctive features of sandy tempestites. In: G. Einsele $\&$ A. Seilacher (eds.) Cyclic and event stratification. Berlin, SpringerVerlag, 333-349.

Shumway G.A. 1953. Rafted pebbles from the deep ocean of Baja California. J. Sed. Pet., 23:24-33.

Soares E.A.A. 1998. Fácies litorâneas glaciais da Formação Nhamundá (Siluriano Inferior), na região de Presidente Figueiredo, AM, Bacia do Amazonas. Centro de Geociências, Universidade Federal do Pará, Dissertação de Mestrado, 98 p.

Soliani Jr. E. 1986. Os dados geocronológicos do Escudo Sul-Riograndense e suas implicações de ordem geotectônica. Instituto de Geociências, Universidade de São Paulo, Tese de Doutoramento, 425 p.

Southard J.B., Lambie J.M., Federico D.C., Pile H.T., Weidman C.R. 1990. Experiments on bed configurations in fine sands under bidirectional purely oscilatory flow, and the origin of hummocky cross-stratification. J. Sed. Pet., 60:1-17.

Spjeldnaes N. 1981. Ice-rafting, an indication of glaciation? Science, 214(4521):687-688.

Thomas G.S.P. \& Connell R.J. 1985. Iceberg drop, dump, and grounding structures from Pleistocene glacio-lacustrine sediments, Scotland. $J$. Sed. Pet., 55:243-249.

Visser J.N.J. \& Loock J.C. 1987. Ice margin influence on glaciomarine sedimentation in the Permo-Carboniferous Dwyka Formation from the southwestern Karoo, South Africa. Sedimentology, 34:929-941.

Walker R.G. \& James N.P. 1992. Facies models. Response to sea level changes.Geological Association of Canada,454p.

Manuscrito A-1269

Recebido em 03 de novembro de 2001

Revisão dos autores em 19 de março de 2003

Revisão aceita em 25 de março de 2003 